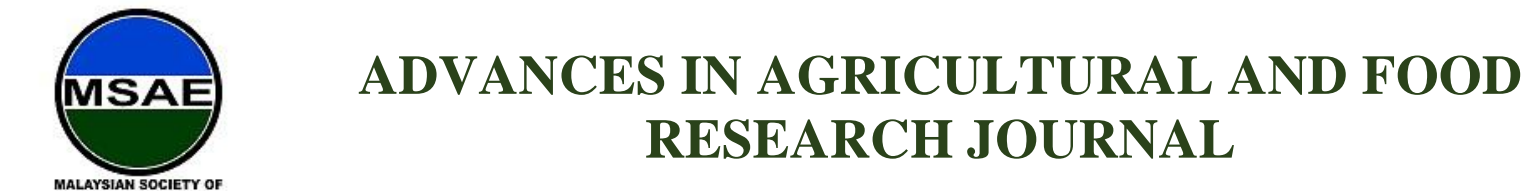

HH PUBLISHER

Original Research Article

\title{
Remote Sensing for Detection of Ganoderma Disease and Bagworm Infestation in Oil Palm
}

\author{
Mohamad Izzuddin Anuar ${ }^{1 *}$, Hamzah Arof ${ }^{2}$, Nisfariza M. Nor ${ }^{2}$, Zulkifli Hashim ${ }^{1}$, Idris Abu Seman ${ }^{1}$, \\ Mohd Mazmira Mohd Masri ${ }^{1}$, Mohd Shukri Ibrahim ${ }^{1}$, Ewe Hong Tat ${ }^{3}$, Chia Ming Toh ${ }^{3}$ \\ ${ }^{1}$ Biological and Sustainability Research Division, Malaysian Palm Oil Board (MPOB), 43000 Kajang, \\ Selangor, Malaysia \\ ${ }^{2}$ Department of Electrical Engineering, Faculty of Engineering, Universiti Malaya, 50603 Kuala \\ Lumpur, Malaysia \\ ${ }^{3}$ Department of Geography, Faculty of Social Sciences and Arts, Universiti Malaya, 50603 Kuala Lumpur, \\ Malaysia \\ *Corresponding author: Mohamad Izzuddin Anuar, Biological and Sustainability Research Division, \\ Malaysian Palm Oil Board (MPOB), 43000 Kajang, Selangor, Malaysia; \\ mohamad.izzuddin@mpob.gov.my; Tel.: 603-87694486; Fax:603-89258215.
}

\begin{abstract}
Two major disease and pest in oil palm are Ganoderma disease and bagworm infestation. Ganoderma disease caused by Ganoderma boninense and bagworm infestation caused by Metisa Plana have caused significant losses to the oil palm industry. Therefore, early detection and control are important to reduce the losses. This paper reviewed the existing approaches, challenges and future trend of aerial remote sensing technology for Ganoderma disease and bagworm infestation in oil palm. The aerial remote sensing technology comprises of multispectral, hyperspectral camera and radar which have different platforms such as satellite, aircraft and Unmanned Aerial Vehicle (UAV). The aerial multispectral and hyperspectral remote sensing analyse spectral signatures from visible and near infrared spectrum range for the detection of disease and pest attacks. Studies have showed that satellite- based multispectral remote sensing only provide moderate accuracy $(<70 \%)$ compared to UAV-based multispectral remote sensing $(>80 \%)$ for the detection of disease and pest infestation. Similarly, our study using multispectral camera onboard UAV showed $90 \%$ of accuracy for moderate and severe Ganoderma disease detection in oil palm. Meanwhile, application of aerial hyperspectral remote sensing for Ganoderma disease demonstrated potential for the early detection of Ganoderma disease in oil palm and in addition, can be used to detect early pest infestation in oil palm based on field spectroscopy results. Other than that, radar remote sensing has also been able to differentiate healthy and infected oil palm through the analysis of radar backscatter image of the foliar, frond and crown of oil palm. As a conclusion, aerial remote sensing provides a better and faster disease and pest infestation detection system compared to ground-based inspection which in turn can
\end{abstract}


provide a more economic and efficient management of disease and pest infestation for large oil palm plantation areas.

Keywords: Oil palm; Ganoderma disease; bagworm infestation; UAV; multispectral; hyperspectral; radar satellite.

Received: $20^{\text {th }}$ June 2020

Received in revised form: $6^{\text {th }}$ December 2020

Accepted: $10^{\text {th }}$ December 2020

Available Online: $3^{\text {rd }}$ January 2021

Citation:Izzuddin MA, Hamzah A, Nisfariza MN, et al. Remote sensing for detection of Ganoderma disease and bagworm infestation in oil palm. Adv Agri Food Res J 2021; 2(1): a0000189. https://doi.org/10.36877/aafrj.a0000189

\section{Introduction}

Oil palm is an important commodity crop and industry in Malaysia. The oil palm industry provides significantly to gross domestic product (GDP), gross national income (GNI) and foreign exchange as well as employment (Kushairi et al., 2018). However, the oil palm industry is still facing a major problem where Ganoderma disease and bagworm (Metisa plana) pest infestation have been found to cause considerable reduction in yield and profit in oil palm plantations (Norman \& Basri, 2010; Idris et al., 2016). The Ganoderma disease in oil palm is caused by Ganoderma sp. which infects the root, bole and lower stem of the oil palm. The infection causes rotting to the oil palm tissue which reduces uptake of water and nutrients from root to the leaves and fruit production (Nuranis et al., 2016). The disease also affects the physiology of oil palm such as chlorophyll and water content and photosynthesis which include gas exchanges (Haniff et al., 2005). These physiology changes due to root infection create stress that can change the spectral signature of the healthy oil palm (Izzuddin, 2010).

Meanwhile, bagworm infestation can cause about 30-40\% yield losses (Basri, 1993). Regular census and aerial spraying of bio-insecticide is important to control the infestation (Kamarudin et al., 2017). Current bagworm infestation detection relies on visual inspection on the ground based on the visual symptom of bagworm presence and damage to the foliar (Cheong et al., 2010), which also changes the spectral signatures of the foliar.

Spectral signature can be defined as a function of the incidental electromagnetic wavelength and material interaction with that section of the electromagnetic spectrum (Horning, 2008). Several studies showed that there were unique spectral signatures of crops changes from healthy towards the diseased and infested that are present in different narrow specific wavelengths (Izzuddin, 2010; Lelong et al., 2010; Shafri et al., 2011; Nordiana et al., 2012; Liaghat et al., 2014). These spectral signatures derived from crops can be extracted from the aerial multispectral and hyperspectral remote sensing image. 
Remote sensing can be defined as the science and practice of acquiring information about an object without actually coming into contact with it (Horning, 2008). In this paper, the context of aerial remote sensing includes satellite and airborne-based remote sensing. There are two types of aerial remote sensing: 1) optical and 2) radar. The optical sensing consists of multispectral and hyperspectral cameras on-board the satellites and airborne platforms that record imagery of spectral signatures from objects on the ground. The airborne platforms can be represented by a piloted aircraft or an Unmanned Aerial Vehicle (UAV). On the other hand, the radar remote sensing consists of radar antenna system on-board a satellite platform that transmits microwave signals from the Earth orbits to the ground and record back the backscatters from the ground objects.

The detection of disease and pest infestation in the field is important to assist in disease and pest control, so as to prevent further losses. Current disease and pest detection technique uses visual inspection or ground census, Ganoderma Selective Medium (GSM), field spectroscopy and also molecular lab-based detection kit for each individual oil palm in the field (Ariffin et al., 1993; Shafri et al., 2011 Idris et al., 2016; Nordiana et al., 2012). As a result, the ground detection requires high cost for labour and time consuming. Hence, a faster detection technique that can cover a wide oil palm area is needed to assist managers to plan and conduct faster control and replanting works to avoid further loss. In this, aerial remote sensing showed the potential as a solution for faster disease and pest detection measures in oil palm.

The optical aerial remote sensing provides imageries that can identify the location and sets apart healthy and diseased or infested crops through the classification of the spectral signatures from an image. The multispectral imaging measures sunlight in a small number (typically 3 to 15) of spectral bands while hyperspectral imaging provides hundreds of narrow bands measured in percentage of reflectance from visible to near infrared spectrum region (Schowengerdt, 2007). Additionally, current advancement in the multispectral and hyperspectral cameras have introduced the use of a light-weight camera that can be mounted onto small UAV at a lower cost compared to previous technology which had bulky and expensive cameras which can only be mounted onto large piloted aircrafts. Meanwhile, radar remote sensing is a satellite-based active imaging system that can capture images during day and night, and does not have cloud cover problem but provide lower spatial resolution. Therefore, in this study, the application of the optical (multispectral and hyperspectral) and radar aerial remote sensing for detection of Ganoderma disease and pest infestation in oil palm was discussed.

\section{Materials and Methods}

The flowchart of methodology is shown in Figure 1. 


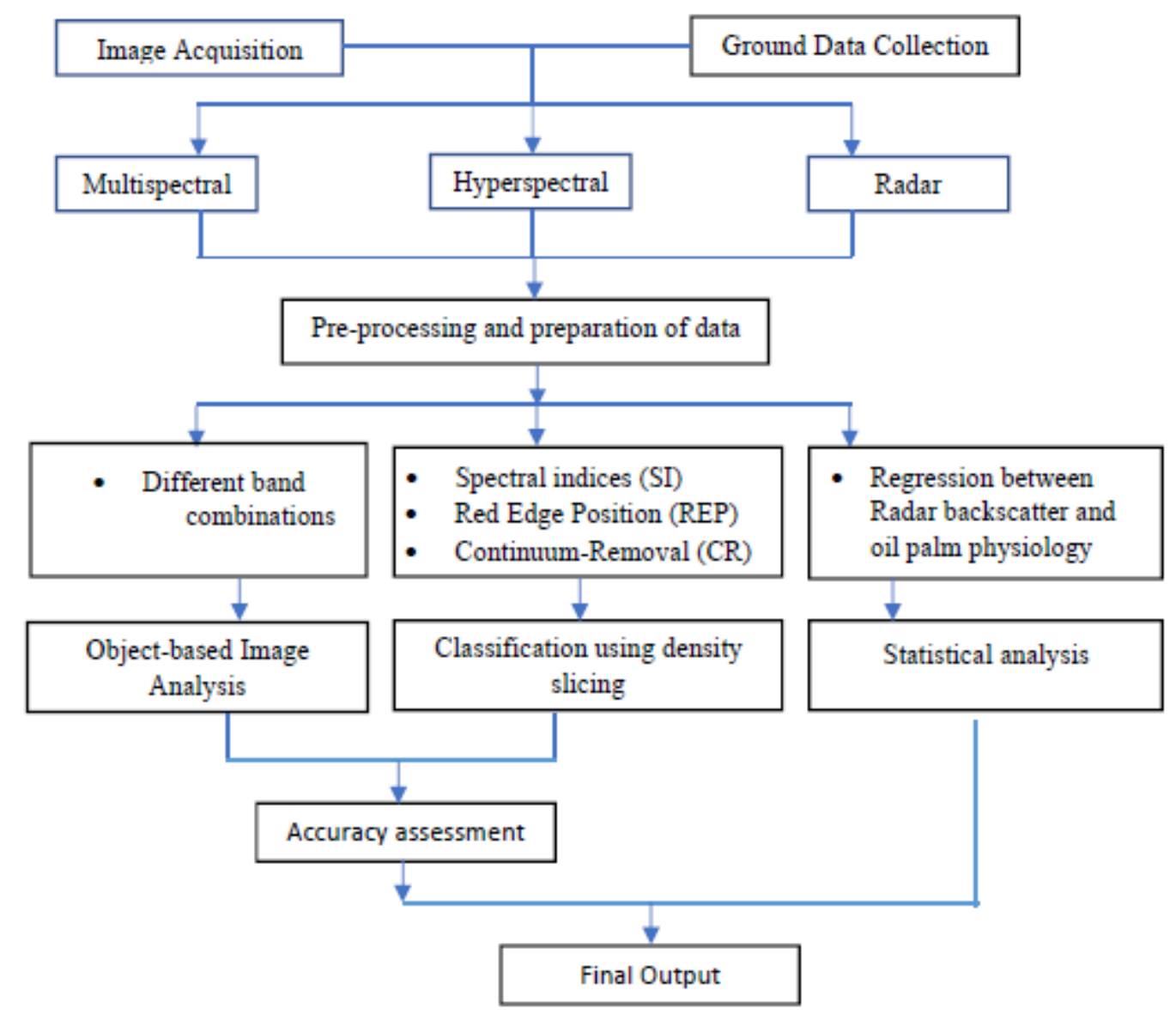

Figure 1. Flowchart of methodology

\subsection{Remote Sensing Images Acquisition}

This study acquired three types of different remote sensing imageries which are: 1) multispectral image from UAV; 2) hyperspectral image from airborne fixed-wing platform; and 3) radar satellite. The multispectral image was acquired using Sequioa multispectral camera mounted on DJI Phantom 4 UAV (Figure 2) over eight years old oil palm area. The multispectral camera acquires four spectral bands which are: 1) green $(G) ; 2)$ red $(R) ; 3)$ red edge (RE); and near infrared (NIR). 

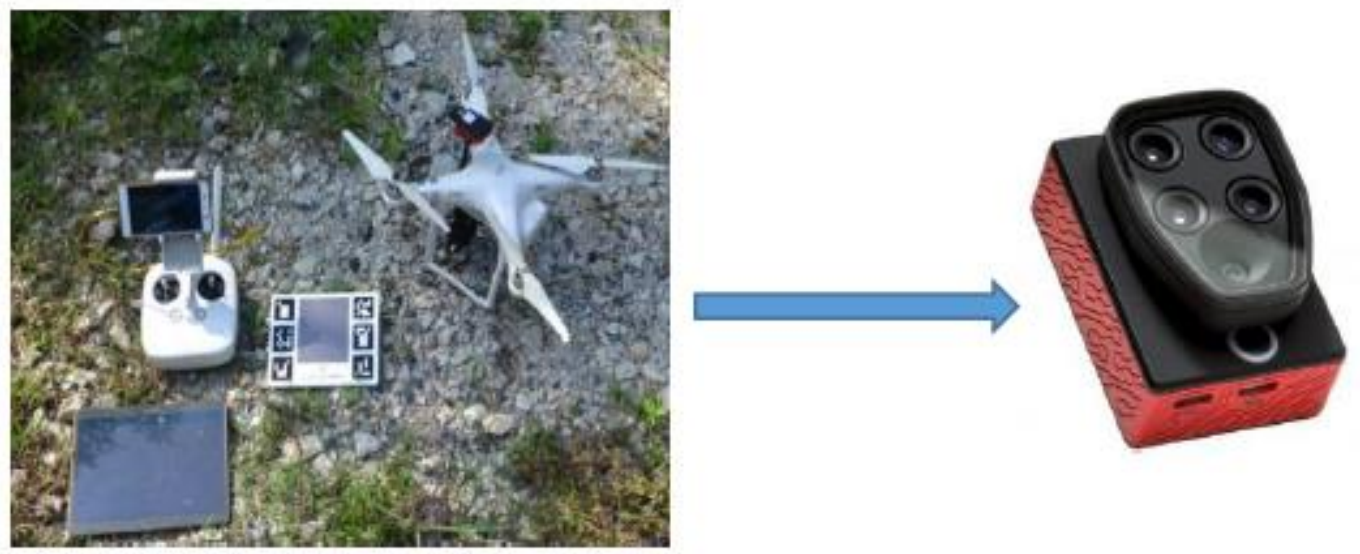

Figure 2. Sequoia multispectral with DJI Phantom 4 UAV system.

Then, the hyperspectral image was acquired using AISA SPECIM Eagle hyperspectral camera on-board a fixed-wing piloted Skyvan aircraft (Figure 3). The hyperspectral camera acquired 128 spectral bands images over 7 and 13 years old oil palm area.
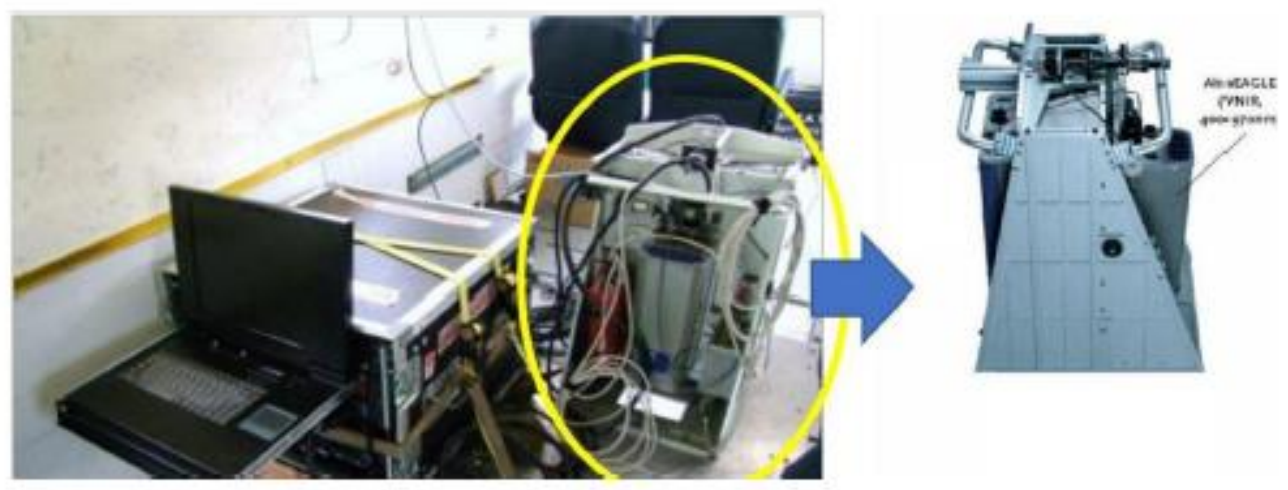

Figure 3. AISA SPECIM Eagle hyperspectral camera on-board Skyvan aircraft.

Radar image was acquired using ALOS-PALSAR satellite (Figure 4) over 8 eight years old oil palm. 


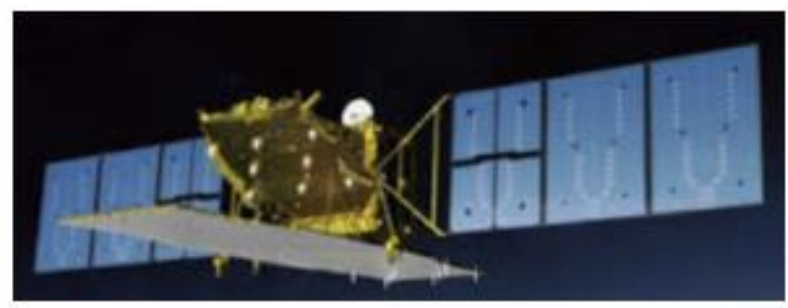

Figure 4. ALOS PALSAR 2 satellite

\subsection{Ground Data Collection}

Ground data collected in this study consisted of ground census of Ganoderma disease and bagworm infestation in the study area. The ground census was conducted using visual inspection of individual oil palm on the ground. The ground census categorised the individual oil palm into four Ganoderma disease severity index (GDSI): 1) healthy (T0); 2) mild/early (T1); 3) moderate (T2); 4) severe (T3) infection of Ganoderma disease in oil palm (Figure 5). The early or mild infections were not included in data collection due to insufficient amount of training data. Only two oil palms were confirmed as T1 during the ground census. The ground census data was digitised and stored in the Geographic Information System (GIS) software to be overlaid onto the remote sensing image for image classification and accuracy assessment purposes.

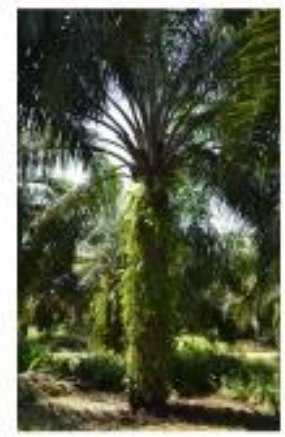

USI $=U$

Healthy

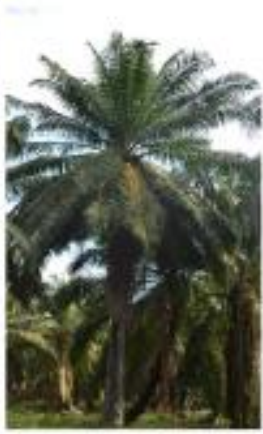

$\mathrm{DSI}=1$

Mild

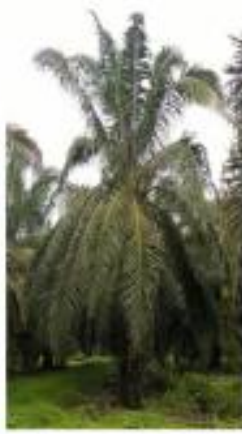

$\mathrm{DSI}=2$

Moderate

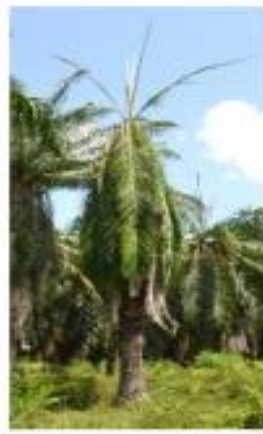

USI $=3$

Severe

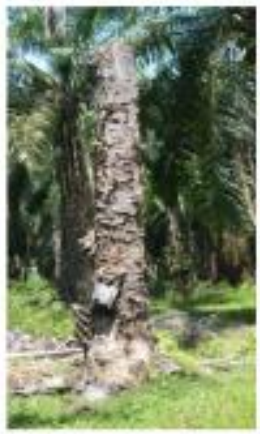

USI $=4$

Dead

Figure 5. The Ganoderma Disease Severity Index (GDSI).

The ground data for Ganoderma disease consisted of the ground census of GDSI that tagged with individual oil palm geographic coordinate information were converted into geospatial data as vector file type and stored in GIS software (ArcGIS 10.3). The ground data for bagworm infestation consisted of healthy (P0) and infested oil palm (P1). The ground 
data was conducted by visual inspection of bagworm existence on the leaves and fronds of oil palm for occurred damages (Kamarudin et al., 2017).

\subsection{Data Pre-Processing and Preparation}

The GDSI data recorded during ground census data were stored in a vector file format in GIS system. The GDSI were tagged with geographical coordinate of each individual oil palm in the study area. The multispectral and hyperspectral images were pre- process for radiometric, geometric, orthorectification and mosaicking using pix4D and Caligeo ENVI 4.3 software. The radar satellite imagery was corrected to backscatter image using ENVI 4.3 software. The pre-processed multispectral image used in this study is shown in Table 1.

Table 1. Multispectral image from satellite and UAV over an oil palm area

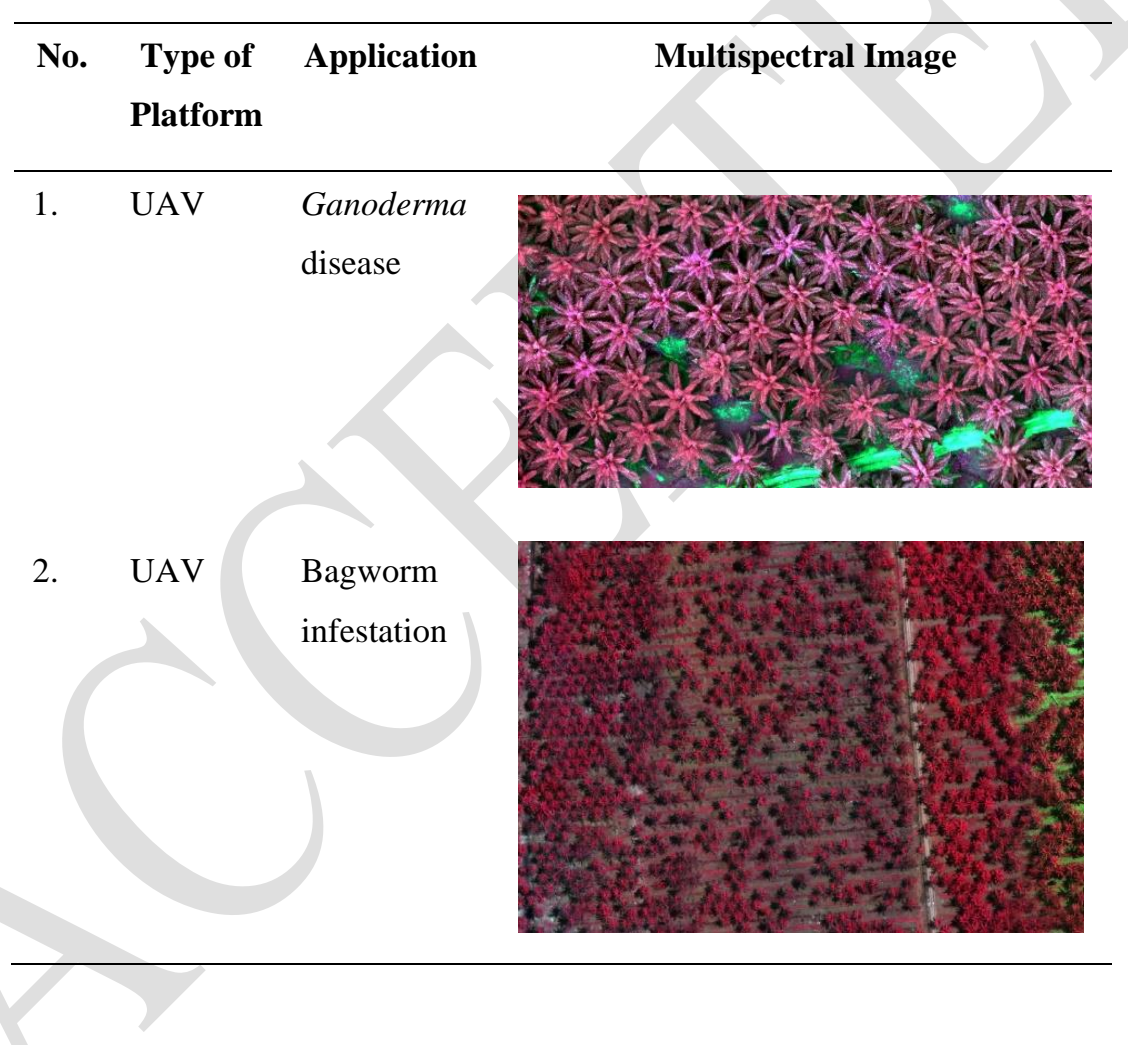

\subsection{Remote Sensing Image Processing}

The multispectral image was processed using Example-Based Image Analysis which is a part of Object based image Analysis (OBIA) methods for classification of four GDSI. The processes were conducted using ENVI 5.0 software. There were five spectral band combinations (Table 2) tested in this study. 
Table 2. List of individual band and different band combinations.

\begin{tabular}{lcc}
\hline No. & $\begin{array}{c}\text { Three-bands } \\
\text { combinations }\end{array}$ & $\begin{array}{c}\text { Four-band } \\
\text { combinations }\end{array}$ \\
\hline $\mathbf{1}$ & G_R_RE & G_R_RE_NIR \\
\hline $\mathbf{2}$ & G_R_NIR & \\
\hline $\mathbf{3}$ & R_RE_NIR & \\
\hline $\mathbf{4}$ & G_RE_NIR & \\
\hline
\end{tabular}

The hyperspectral image was processed using several spectral indices (Table 3), red edge position (REP) (Table 4) and continuum-removal (Table 5).

Table 3. Hyperspectral spectral indices.

\begin{tabular}{cl}
\hline No. & \multicolumn{1}{c}{ Spectral indices } \\
\hline 1 & Normalised Difference Vegetation Index (NDVI) \\
2 & Simple Ratio Index (SRI) \\
3 & Enhanced Vegetation Index (EVI) \\
4 & Vogelmann Red Edge Index (VREI) \\
5 & Carotenoid Reflectance Index 2 (CRI 2) \\
\hline
\end{tabular}

Table 4. Red edge position (REP).

\begin{tabular}{cl}
\hline No. & \multicolumn{1}{c}{ Red Edge Position (REP) } \\
\hline 1 & Linear Interpolation(NDVI) \\
2 & Simple Ratio Index (SRI) \\
3 & Enhanced Vegetation Index (EVI) \\
4 & Vogelmann Red Edge Index (VREI) \\
\hline
\end{tabular}

Table 5. Continuum-removal (CR).

\begin{tabular}{cl}
\hline No. & \multicolumn{1}{c}{ Continuum-removal (CR) } \\
\hline 1 & Continuum Removed Reflectance(CRR) \\
2 & Band depth (BD) \\
3 & Normalised Band Depth (NBD) \\
4 & Band Depth Normalised to Area(BDNA) \\
\hline
\end{tabular}

Other than that, the radar image was processed using radar coefficients into radar backscatter values. The radar backscatter values were regressed with several oil palm physiological parameters which were: 1) number of frond and pinnae; 2) height and circumference of trunk; 3) length, depth, width and moisture content of frond; 4) length, width and moisture content of pinnae. The biophysical parameters were regressed with three levels of disease severities which were healthy, mild, and severe. 
The OBIA method used to analyse the multispectral image was conducted by Izzuddin et al. (2020). The outputs of the OBIA were then assessed using confusion matrix. The results for hyperspectral image analysis were analysed using comparative statistical analysis (Nisfariza, 2012; Izzuddin et al., 2018). The radar image was analysed using statistical regression analysis (Toh et al., 2018).

\section{Results and Discussion}

\subsection{Ground Data}

The ground census recorded manually in the field was digitised and stored in GIS database using ArcGIS 10.3 software. The data was divided into training and testing data. The training data was then used to train the classification algorithm while the testing data was used for accuracy assessment of the image classification output.

\subsection{Multispectral Image}

For Ganoderma disease detection, the multispectral image was processed using OBIA into T0, T2, T3 and T4 and the accuracy assessment was conducted using the confusion matrix. The results are shown in Table 6.

Table 6. Accuracy assessment of classification output for individual band and different band combinations.

\begin{tabular}{ccccccc}
\hline \multicolumn{7}{c}{ Category Accuracy (\%) } \\
\hline $\begin{array}{c}\text { Band } \\
\text { combinations }\end{array}$ & Rank & T0 & T2 & T3 & Overall Accuracy (\%) & $\begin{array}{c}\text { Kappa } \\
\text { Coefficient } \\
\text { G_R_RE }\end{array}$ \\
G_R_NIR & 1 & 85.1 & 76.9 & 41.7 & 82.0 & 0.8693 \\
G_R_N_NIR & 3 & 95.03 & 76.9 & 58.3 & 91.8 & 0.9426 \\
R_RE_NIR & 90.6 & 84.6 & 33.3 & 86.9 & 0.9665 \\
G_RE_NIR & 4 & 87.8 & 84.6 & 58.3 & 85.9 & 0.7929 \\
G_R_RE_NIR & 2 & 93.4 & 76.9 & 41.7 & 89.3 & 0.8941 \\
\hline
\end{tabular}

The results showed that the multispectral image was unable to distinguish between healthy and early infection of Ganoderma disease in oil palm but have high accuracy in discriminating between healthy, moderate and severe Ganoderma disease infection. The best band combination to differentiate between healthy, moderate and severe infection is the $G$, $\mathrm{R}$ and NIR band combinations (Figure 6). 


\begin{tabular}{l||l|l|l|l|}
\hline Healthy (DSI=0) & Mild (DSI=1) & Moderate (DSI=2) & Severe (DSI=3) \\
True Colour \\
(Red, Green, Blue)
\end{tabular}

Figure 6. Comparison of true colour band combinations with the best false colour band combinations for Ganoderma disease detection in oil palm.

For bagworm infestation detection, the analysis was only conducted using multispectral imagery. The image obtained was analysed for comparison of healthy and infested oil palm. The results suggested that band combinations of RE, R and $\mathrm{G}$ is the best to visually differentiate healthy and infested oil palm (Figure 7).

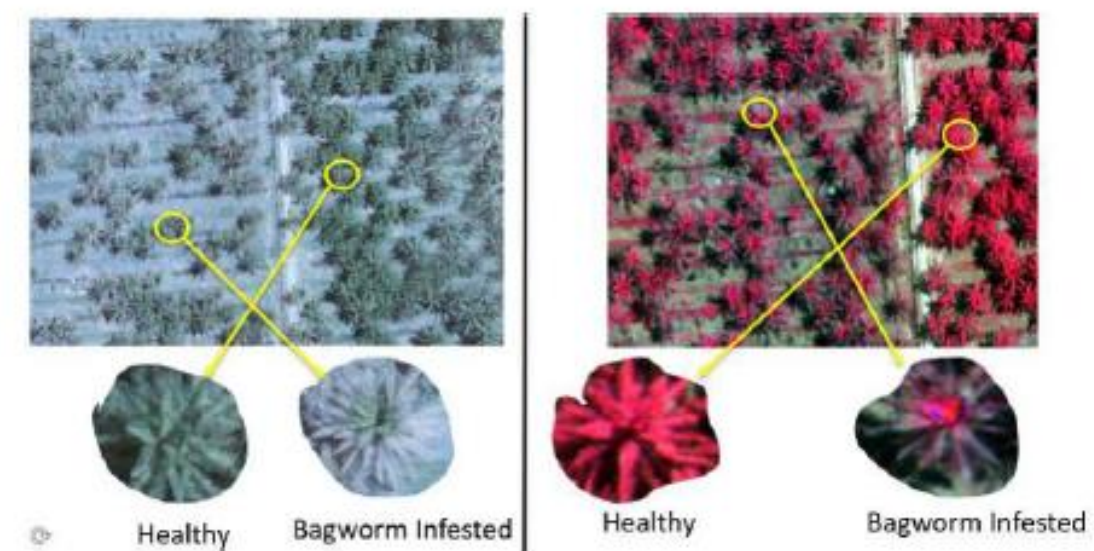

Figure 7. Comparison of true colour band combinations with the best false colour band combinations for bagworm infestation detection in oil palm.

\subsection{Hyperspectral Image}

The hyperspectral image was processed using the spectral indices, REP and also continuum-removal. The results showed that there are no spectral indices and that REP had the capability for early detection of Ganoderma disease in oil palm. However, early detection showed potential by using Band-Depth Normalised to Area (BDNA) in 
Continuum-Removal method (Figure 8). On the other hand, the BDNA had low accuracy in classifying moderate and severe infections of Ganoderma disease in oil palm. There is a need to integrate the CR methods with SI and REP method to enable the classification of all Ganoderma disease severities.

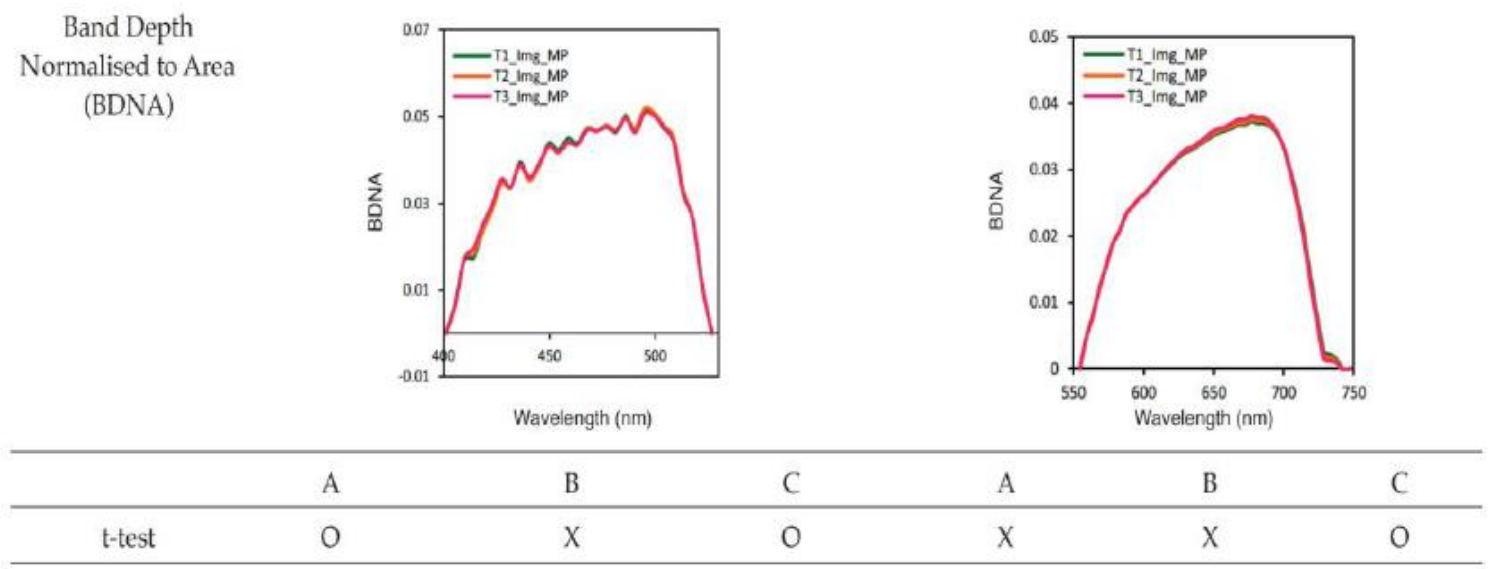

Figure 8. Results of Continuum-Removal (CR) analysis for Band Depth Normalised to Area (BDNA) Note: Results for $t$-test - O (significant difference); and X (no significant difference). $p$-value -0.05 with $95 \%$ confidence level. T1 (healthy), T2 (moderate) and T3 (severe) A - T1 vs. T2, B - T2 vs. T3, C- T1 vs. T3

\subsection{Radar Satellite}

Several parameters were correlated with the increase of disease severity index which include the number of fronds, number of pinnae, frond length and petiole width. The results showed that the $\mathrm{HH}$ polarization decreases drastically while VV undergoes slight decrease in backscatters with increasing disease severity index on 8 years old oil palm. Meanwhile, there were increases in backscatter for all polarization with a small increase in HV/VH for 16 years old oil palm (Figure 9 ). 
8 years old oil palm

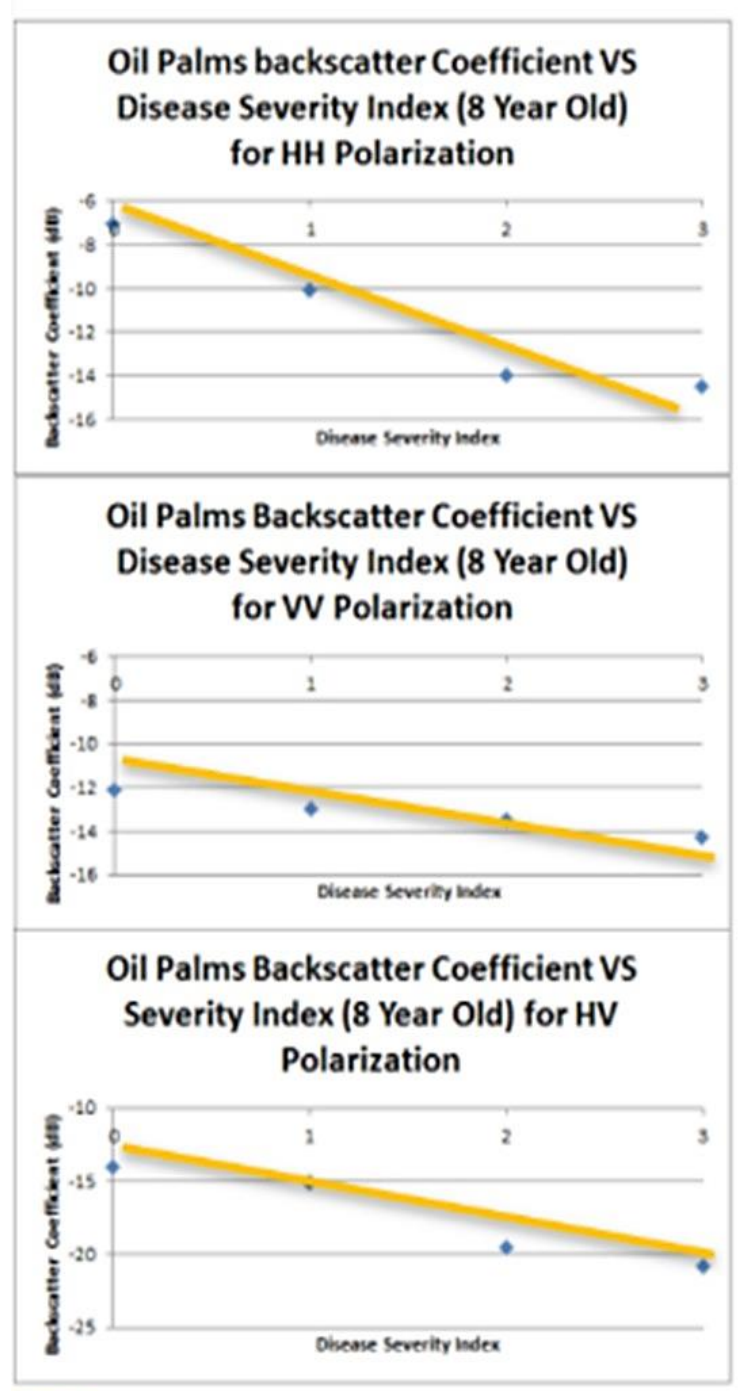

16 years old oil palm

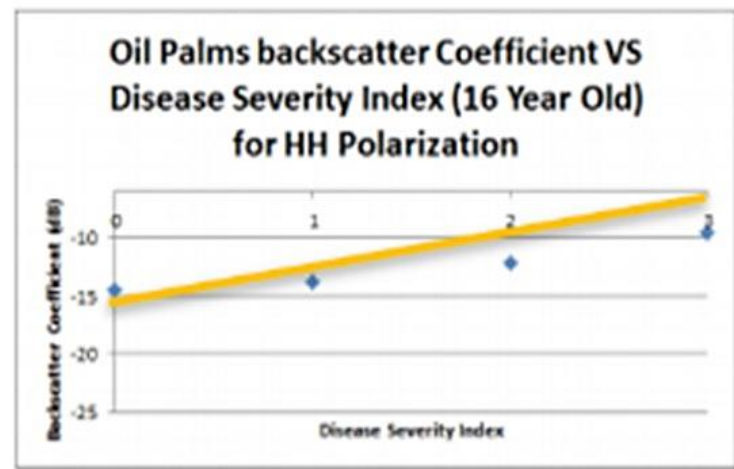

Oil Palms backscatter Coefficient VS

Disease Severity Index (16 Year Old) for VVPolarization

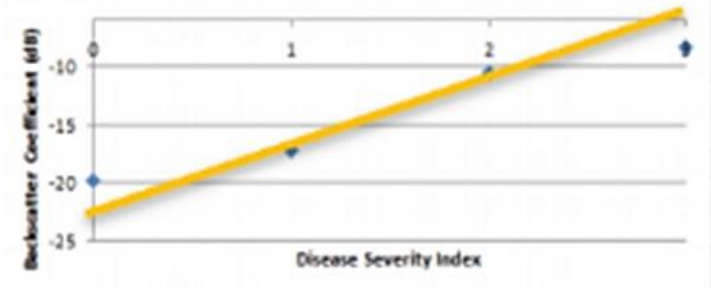

Oil Palms backscatter Coefficient VS

Disease Severity Index (16 Year Old) for HV Polarization

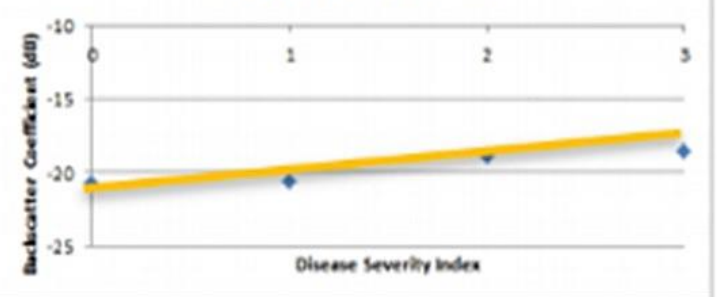

Figure 9. Results of radar imagery to differentiate, healthy, mild and severe Ganoderma disease infection in oil palm.

\section{Conclusion}

Aerial remote sensing using multispectral, hyperspectral and radar sensors were seen to be able to provide assistance for large scale Ganoderma disease and bagworm infestation detection in oil palm. The multispectral imaging was capable to differentiate between healthy, moderate and severe infection with overall accuracy more than $90 \%$. However, it was deemed not feasible to detect early (mild) infection of Ganoderma BSR disease in oil palm. Meanwhile, the hyperspectral imaging was able to differentiate between healthy, mild and other severity of Ganoderma BSR disease in oil palm using Continuumremoval algorithm with $p$-value $<0.05$ using the t-test. Other than that, Synthetic Aperture Radar (SAR) image showed that HH and VV polarisation of L-Band radar also with $p$-value 
$<0.05$ using the $t$-test image has the capability for detection of the Ganoderma disease in oil palm. This study also showed that the multispectral false colour composite has the capability to differentiate between healthy and bagworm-infested oil palm. For future works, analysis of aerial remote sensing image using Artificial Intelligence (AI) and Deep Learning (DL) could facilitate better disease infection and pest infestation detection for precision agriculture in oil palm.

Acknowledgement: The researchers would like to thank the staffs of Malaysian Palm Oil Board (MPOB), UM and UTAR for their assistance.

Funding: This research was supported by the Malaysian Palm Oil Board (MPOB)

Conflicts of Interest: The authors declare no conflict of interest, and also the funders had no role in the design of the study; in the collection, analyses, or interpretation of data; in the writing of the manuscript, or in the decision to publish the results.

\section{References}

Ariffin, D., Idris, A. S. \& Khairudin, H. (1993). Confirmation of Ganoderma infected palm by drilling technique. Paper presented at the Proceedings of the 1993 PORIM International Palm Oil Congress: Update and Vision (Agriculture) (Jalani, S., Ariffin, D., Rajanaidu, N., Tayeb, D., Paranjothy, K., Basri, M. W., Henson, I. E. \& Chang, K. C. eds.): 735-738.

Basri, M. W. (1993). Life history, ecology, and economic impact of the bagworm, Metisa plana Walker (Lepidoptera: Phocidae), on the oil palm, Elais Guineensis Jacquin (Palmae). Ph.D thesis, University of Guelp, Ontario, Canada.

Cheong, Y. L., Sajap, A. S., Hafidzi, M. N. et al. (2010). Outbreaks of bagworms and their natural enemies in an oil palm, Elaeis Guineensis, Plantation at Hutan Melintang, Perak, Malaysia. Journal Entomology. 7(3), 141-151. doi: https://doi.org/10.3923/je.2010.141.151.

Haniff, M. H., Ismail, S. \& Idris, A. S. (2005). Gas exchange responses of oil palm to Ganoderma boninense infection. Asian Journal Plant Science, 4(4), 438-444. doi: https://doi.org/10.3923/ajps.2005.438.444

Horning, N. (2008). Remote sensing, reference module in earth systems and environmental sciences encyclopedia of ecology. Encyclopedia of Ecology, 2986-2994.

Idris, A. S., Nur Rashyeda, R., Mohd Hefni, R. et al., (2016). Standard operating procedures (SOP) guidelines for managing Ganoderma disease in oil palm. Malaysian Palm Oil Board (MPOB), Malaysia, 1-41.

Izzuddin, M. A. (2010). Early detection of Ganoderma disease in oil palm (Elais Guinenesis) using field spectroscopy. MSc Thesis., Universiti Putra Malaysia.

Izzuddin, M. A., Nisfariza, M. N., Ezzati, B. et al. (2018). Analysis of airborne hyperspectral image using vegetation indices, red edge position and continuum removal for detection of Ganoderma disease in oil palm. Journal Oil Palm Research, 30(3), 416-428. doi: https://doi.org/10.21894/jopr.2018.0037 
Izzuddin, M.A., Hamzah, A, Nisfariza, M . N. et al. (2020). Analysis of multispectral imagery from unmanned aerial vehicle (UAV) using object-based image analysis for detection of Ganoderma disease in oil palm. Journal Oil Palm Research, 32(3), 497-508. doi: https://doi.org/10.21894/jopr.2020.0035

Kushairi, A., Loh, S. K., Azman, I. et al. (2018). Oil palm economic performance in Malaysia and R\&D progress in 2017. Journal Oil Palm Research, 30(2), 163-195. doi: https://doi.org/10.21894/jopr.2018.0030

Kamarudin, N., Siti Ramlah, A. A., Mazmira, M. M. M., et al. (2017). Controlling Metisa Plana Walker (Lepidoptera: Psychidae) outbreak using Bacillus thuringiensis at an oil palm plantation in Slim River, Perak, Malaysia. Journal Oil Palm Research, 29(1), 47-54. doi: https://doi.org/10.21894/jopr.2017.2901.05

Lelong, C. C. D., Roger, J. M., Brégand, S. et al. (2010). Evaluation of oil-palm fungal disease infestation with canopy hyperspectral reflectance data. Sensors 10(1), 734-747. doi: https://doi.org/10.3390/s100100734

Liaghat, S., Ehsani, R., Shattri, M, et al. (2014). Early detection of basal stem rot disease (Ganoderma) in oil palms based on hyperspectral reflectance data using pattern recognition algorithms. International Journal Remote Sensing, 35(10), 3427-3439. doi: https://doi.org/10.1080/01431161.2014.903353

Nisfariza, M. N. (2012). Early detection of Ganoderma basal stem rot disease of oil palm by hyperspectral remote sensing. $\mathrm{PhD}$ thesis, University of Nottingham, United Kingdom.

Nordiana, A. A., Wahid, O., Rohani, K. et al. (2012). Remote sensing measurement for detection of bagworm infestation in oil palm plantation. MPOB Information Series No. 502. http://palmoilis.mpob.gov.my/publications/TOT/TT-502.pdf.

Norman, K. \& Basri M. W. (2010). Interactions of the bagworm, Pteroma pendula (Lepidoptera: Psychidae), and its natural enemies in an oil palm plantation in Perak. Journal Oil Palm Research, 22, 758-764.

Nuranis, I., Kamaruzaman, S., Khairulmazmi, A., et al. (2016). Leaf nutrient status in relation to severity of Ganoderma infection in oil palm seedlings artificially infected with Ganoderma boninense using root inoculation technique. Oil Palm Bulletin, 72, 25-31.

Schowengerdt, R. (Ed.). (2007). Remote sensing: Models and methods for image processing (3rd ed.). Academic Press.

Shafri, H. Z. M., Izzuddin, M. A., Idris, A. S. et al. (2011). Spectral discrimination of healthy and Ganodermainfected oil palms from hyperspectral data. International Journal Remote Sensing, 32(22), 7111-7129. doi: https://doi.org/10.1080/01431161.2010.519003

Toh, C. M., Izzuddin, M. A., Ewe, H. T. et al. (2018, October 31). A study on basal stem rot in oil palm with L band Synthethic Apecture Radar (SAR). IEEE Workshop on Geoscience and Remote Sensing 2018. UiTM, Shah Alam, Selangor, Malaysia. 